CDD: 501

\title{
AS LEIS DA NATUREZA E OS CASOS DE TOOLEY
}

\section{RODRIGO REIS LASTRA CID}

Departamento de Filosofia

Universidade Federal do Rio de Janeiro

Largo de S. Francisco de Paula 1/320-B

20051-070 RIO DE JANEIRO, RJ

BRASIL

rodrigorlcid@hotmail.com

Received: 09.03.2012; Revised: 21.08.2012; Accepted: 28.11.2012

Resumo: Os objetivos deste artigo são: (1) apresentar quatro teorias com relação à natureza das leis naturais, (2) mostrar que apenas uma delas é capaz de responder satisfatoriamente aos Casos de Tooley e (3) indicar por que tais casos são relevantes para a nossa ontologia. Estes objetivos são importantes, pois o conceito de "lei natural" é utilizado em muitos, se não todos, os domínios das ciências e em muitos domínios da filosofia; e, se tais casos forem possíveis, eles serão situações que precisariam ser adequadamente descritas. Se uma e apenas uma teoria puder descrever tais casos adequadamente, haverá fortes razões para preferir tal teoria frente às outras.

Palavras chave: Filosofia. Metafísica. Metafísica das Leis Naturais. Leis Não Instanciadas.

Abstract: The purposes of this paper are: (1) to present four theories of the nature of natural laws, (2) to show that only one of them is capable of adequately answering to Tooley's Cases, and (3) indicate why these cases are relevant for our ontology. These purposes are important since the concept of "natural law" is used in many (if not all) realms of natural science and in many branches of philosophy; if Tooley's cases are possible, they represent situations that must be adequately described. If there is only one theory that can adequately describe such cases, there are strong reasons to prefer this theory over the other ones.

Keywords: Philosophy. Mataphysics. Metaphysics of Natural Laws. Non-Instantiated Laws

Manuscrito - Rev. Int. Fil., Campinas, v. 36, n. 1, p. 67-101, jan.-jun. 2013. 


\section{Introdução}

As ciências nos falam sobre inúmeras leis científicas. Alguns exemplos são a lei da gravitação universal, as leis de Newton, as leis planetárias de Kepler, as leis dos gases ideais, entre outras. Elas nos dizem quais são as consequências da instanciação de certas propriedades. Por exemplo, a lei da gravitação universal nos diz que dois objetos com as propriedades de ter respectivamente as massas $\mathrm{m}_{1}$ e $\mathrm{m}_{2}$ se atraem por meio de uma força que é proporcional às suas massas e que é inversamente proporcional ao quadrado de sua distância. Essa lei estabelece que as propriedades de ter a massa $\mathrm{m}_{1}$ e de ter a massa $\mathrm{m}_{2}$, instanciadas em objetos diferentes, têm a consequência de gerar, nos objetos, uma outra propriedade, que é a atração que ocorre entre eles. As leis científicas, como a lei da gravidade, são hipóteses sobre quais são as leis naturais que vigem no mundo. Os cientistas, ao formularem suas leis científicas pretendem que elas falem sobre o mundo, pretendem que elas sejam leis da natureza. Mas as leis da natureza, se existirem, serão objetos independentes das teorias científicas que as tentam apreender, sendo por sua vez os veridadores ${ }^{1}$ das leis científicas.

Mas falar sobre leis da natureza não é utilizar um discurso sem divergências filosóficas. Muitos teóricos - como, por exemplo, Stephen Mumford (2004) - negam que haja qualquer lei da natureza. Enquanto outros, como Michael Tooley (1977) sustentam que há leis como algo um tanto substantivo. Há inúmeras teorias filosóficas que discordam com relação à natureza das leis e os papéis teóricos atribuíveis a elas. Por exemplo, se as leis da natureza forem meras regularidades, como

\footnotetext{
1 O veridador de uma proposição é algo existente (um estado de coisas, por exemplo) que faz tal proposição ser verdadeira. Neste caso, um veridador de uma lei científica é aquilo que existe que a faz verdadeira. Este neologismo no português do Brasil já está em uso no português de Portugal para traduzir o termo anglo-saxão "truthmaker".
} 
pretende a teoria do regularismo, então as leis não poderão ter o papel de explicar a existência das regularidades, pois uma regularidade não pode explicar por que ela mesma existe. No entanto, se elas forem algo além de regularidades, como pretendem substantivistas, como Tooley (1977) e David Armstrong (1983), talvez possam. Para falarmos seriamente sobre leis da natureza, precisamos ter uma teoria das leis que fundamente o nosso discurso, pois se não a tivermos, não seremos aptos a utilizar o conceito de lei natural para nenhum papel teórico interessante. Uma teoria filosófica completa das leis naturais nos diz argumentativamente se leis existem, qual a natureza dessas leis e quais papéis teóricos elas têm. Indicar qual é a natureza de uma lei é caracterizar o substrato ontológico que fundamenta sua existência, caso ela exista, ou dizer que não há um tal substrato ontológico, caso ela não exista. E de acordo com o substrato escolhido, ou com a falta de um, alguns papéis teóricos tornam-se disponíveis ou indisponíveis às leis.

E, além disso, as teorias sobre as leis naturais podem ser pensadas como vantajosas ou desvantajosas de acordo com se as características de suas leis naturais são capazes de sustentar uma lei científica verdadeira. Uma lei científica verdadeira é tal que expressa uma lei natural, e uma lei natural é o veridador (talvez junto com outras coisas) dos contrafactuais cujas antecedente e consequente são suas instâncias ${ }^{2}$. Por exemplo, se há uma lei científica que nos diz que o sal se dissolve em água ${ }^{3}$, então se tal lei for verdadeira, será uma lei da natureza que o sal se dissolve em água, e todo contrafactual que nos falar de uma certa relação entre o sal e a água - como o contrafactual

2 Há algumas teorias, como a de Lange (2009), que tentam defender que não são as leis que explicam os contrafactuais (ou melhor, os condicionais subjuntivos), mas que são os contrafactuais que fundamentalmente explicam as leis, dado que as leis são formuláveis por meio deles. Se tal caminho for seguido, teremos o problema de não podermos dar uma explicação para todos os contrafactuais em termos de leis, tal como seriam capazes as leis científicas, se forem verdadeiras.

3 Essa seria uma lei derivada da Lei de Coulomb, segundo Bird (2001).

Manuscrito - Rev. Int. Fil., Campinas, v. 36, n. 1, p. 67-101, jan.-jun. 2013. 
"se eu tivesse colocado algum sal em alguma água em certas condições, o sal teria se dissolvido em água" - será verdadeiro em virtude da lei de que o sal se dissolve em água. Assim, se as leis naturais produzidas pelas teorias filosóficas da natureza das leis naturais têm essa força contrafactual, elas se ajustam à visão científica de leis. Porém, se produzirem leis que não têm tal propriedade, então elas estariam se afastando das ciências e se tornando incompatíveis com elas. O que defenderei aqui é que apenas uma das teorias da natureza das leis, se modificada, explica a contrafactualidade dos Casos de Tooley. Mas não sem antes apresentar as teorias.

Primeiramente, com relação à existência de leis da natureza, há em princípio duas posições filosóficas disponíveis: o realismo e o antirealismo. $\mathrm{O}$ realismo nos diz que as leis da natureza realmente existem e que sua existência é independente da nossa mente. Por sua vez, o antirealismo nos diz que as leis não existem realmente ou que sua existência é dependente de nossa mente.

Ao aceitarmos o realismo ou o anti-realismo, temos de nos posicionar também com relação à natureza das leis naturais ou com relação à natureza do mundo sem leis. As principais teorias nos dizem:

(i) que as leis são regularidades,

(ii) que não há leis universais, embora haja conexões necessárias entre particulares, e

(iii) que as leis são conexões necessárias entre propriedades universais. ${ }^{4}$

$4 \quad$ Há outras posições também, como a posição de Brian Ellis (2001) de que as leis são tipos sendo caracterizados por suas propriedades essenciais e como a posição de Lange (2009) de que as leis são irredutíveis e são caracterizadas por fazerem parte do conjunto com estabilidade subnômica. Tais posições têm bastante especificidades teóricas, mas que não serão trabalhadas neste artigo. No entanto, como estamos fazendo uma discussão geral entre realismo e anti-realismo, pretendemos que nossa discussão abarque tanto as posições de Ellis, quanto de Lange, na medida em que eles são, ou

Manuscrito - Rev. Int. Fil., Campinas, v. 36, n. 1, p. 67-101, jan.-jun. 2013. 
E, além de sermos realistas ou anti-realistas, é preciso dizer se pensamos que há ou não conexões necessárias no mundo, pois os papéis teóricos atribuíveis às leis mudam de acordo com se aceitarmos ou não que elas expressam/são conexões necessárias. $\mathrm{O}$ contingencialismo é a tese de que não existem conexões necessárias na natureza e o necessitarismo é a tese de que elas existem (sejam ou não leis universais). ${ }^{5}$

Um anti-realista necessitarista nega que existam leis universais da natureza e, ao mesmo tempo, aceita que existem conexões necessárias na natureza. Ele diria que não podemos inferir a existência de leis a partir da existência de conexões necessárias; a partir de conexões necessárias, poderíamos apenas inferir a existência de uma estrutura modal para o mundo - tal como a posição de Mumford (2004, parte 2). Ele diria que podemos reduzir a lei de que o sal se dissolve em água a disposições das próprias propriedades dos sais e das águas particulares. Não haveria lei alguma para além das propriedades disposicionais que estão nos sais e águas particulares. Como essas propriedades disposicionais estabeleceriam conexões necessárias entre estímulos e manifestações, elas forneceriam, segundo o anti-realista necessitarista, toda a necessidade que precisamos para dar conta das leis naturais. Assim, do fato de o sal ter de se dissolver em água, não

parecem ser, respectivamente, um anti-realista e um realista com relação a leis. Ellis parece ser anti-realista necessitarista por sua teoria fazer as leis dependerem dos poderes das coisas e Lange parece ser um realista necessitarista por pensar que existem leis irredutíveis que explicam as coisas.

5 Quando falamos aqui de conexões necessárias, não precisamos falar sobre conexões existentes em todos os mundos possíveis. A princípio essa conexão necessária poderia ser tanto a necessidade forte, que se caracteriza pela existência em todos os mundos possíveis, quanto a necessidade fraca, que é a existência nos mundos possíveis em que existem as instâncias dos universais, ou ainda pela relação de necessitação contingente, que garantiria a regularidade apenas no mundo atual. A escolha de um tipo de conexão necessária determina em parte a força contrafactual que uma lei terá.

Manuscrito - Rev. Int. Fil., Campinas, v. 36, n. 1, p. 67-101, jan.-jun. 2013. 
precisamos inferir a existência de uma lei de que ele se dissolve em água, mas podemos inferir a existência de uma rede modal entre as propriedades das coisas particulares, tal como faz Mumford (2004). Para ele, seria a natureza da própria propriedade que implicaria a sua conexão necessária com outras propriedades, e não as leis da natureza. Essa seria uma perspectiva que toma as leis como internas às próprias propriedades e, portanto, redutíveis a estas. ${ }^{6}$

Por sua vez, um anti-realista contingencialista rejeita a existência das leis e de conexões necessárias. Ele diria que tudo que há são conjunções constantes de propriedades sem nenhuma conexão necessária e nem nenhuma lei da natureza. Há apenas fatos regulares expressos por condicionais universais, verdadeiras e contingentes. ${ }^{7}$

Contrariamente, os realistas necessitaristas acreditam tanto que há leis externas às propriedades, quanto que há conexões necessárias na natureza, e identificam pelo menos alguma dessas conexões necessárias com as leis universais da natureza. Os realistas necessitaristas pensam que as leis da natureza são relações externas entre propriedades universais $^{8}$, ou seja, relações entre propriedades universais não

6 Diferentemente do substantivismo in rebus (perspectiva realista da qual falaremos posteriormente), que nos diz que as conexões necessárias entre as propriedades são externas e independentes da natureza das propriedades. E, por isso, formam leis da natureza.

Outra versão do anti-realismo contingencialista é o projetivismo quanto às leis. Este diria que as leis naturais são apenas projeções nossas na realidade, mas que não existem de fato. $\mathrm{O}$ projetivismo nômico pode ser pensado em analogia com o projetivismo moral de Blackburn (1993).

8 Os universais são atributos instanciáveis. Eles são uma tentativa de solução para o problema filosófico da semelhança (existem outras tentativas de solução), assim como também servem para dar um tratamento de outros problemas, como o da referência de termos abstratos singulares, o da natureza das leis naturais e o da natureza dos objetos matemáticos. De modo breve, o problema da semelhança é o de como explicar a existência de semelhança entre diferentes objetos. A solução dos universais nos diz que a semelhança é explicada pelo fato de ambos os objetos instanciarem a mesma propriedade

Manuscrito - Rev. Int. Fil., Campinas, v. 36, n. 1, p. 67-101, jan.-jun. 2013. 
implicadas pela natureza ou identidade das mesmas. Eles se dividem em dois tipos, de acordo com a concepção de propriedade universal aceita. É possível aceitar um aristotelismo das propriedades, tomando-as como algo que está presente nas coisas, como algo imanente, como universais in rebus. E também é possível aceitar um platonismo das propriedades, tomando-as como algo que é independente das coisas, como algo transcendente, como universais ante rem.

Por sua vez, os realistas contingencialistas pensam que não há conexões necessárias na natureza, embora acreditem que há leis naturais; e eles são um dos maiores opositores do realismo necessitarista. Uma forma conhecida de realismo contingencialista é o regularismo. Esta é a posição que nos diz que as leis da natureza existem e são apenas as regularidades acidentais expressas por proposições gerais, condicionais e intemporalmente verdadeiras (ou um tipo dessas regularidades), que são chamadas de "regularidades humeanas". Se aceitamos o regularismo, então torna-se obviamente verdadeiro que há leis, pois é óbvio que há proposições universais, gerais, condicionais e verdadeiras. Contudo, o regularismo não aceita que as leis que existem são conexões necessárias.

O problema de não aceitar a existência de conexões necessárias é que as leis regularistas não serão capazes de cumprir os papéis que motivam uma teoria realista das leis, pois elas não poderão explicar por que as coisas são como são, e não são de outro modo, e também não poderão explicar como é possível que algo tenha um poder. E não o poderão porque o fato de as coisas serem de um modo não pode explicar por que elas são desse modo, e não de outro, e porque o fato de algo ter um poder não explica como é possível que algo tenha um poder. O regularismo, portanto, é um anti-realismo das leis motivadas pelo realismo. Pois os papéis atribuídos às leis pela motivação realista só podem ser representados pelas leis dos realistas necessitaristas.

universal. A divergência que exporei a seguir espelha a divergência que surge na tentativa de explicar o que queremos dizer com "mesma".

Manuscrito - Rev. Int. Fil., Campinas, v. 36, n. 1, p. 67-101, jan.-jun. 2013. 
Apenas algo que torna uma ocorrência necessária, em algum sentido de "necessária", pode nos dizer por que a ocorrência aconteceu em vez de não acontecer - coisa que interessa ao realista (e também ao cientista) responder.

O regularismo tem, na verdade, uma motivação profundamente anti-realista, pois sua afirmação de que as leis não são nada mais que regularidades é motivada por sua vontade de remover o caráter necessitarista das leis, tornando-as puras descrições da realidade, sem nenhum tipo de elemento que pareça não ser descritivo. $O$ regularismo toma as leis do realismo necessitarista, e conexões necessárias em geral, como coisas misteriosas. O próprio Hume, conhecido regularista ${ }^{9}$ diria:

All events seem entirely loose and separate. One event follows another; but we never can observe any tie between them. They seem conjoined, but never connected. And as we can have no idea of any thing which never appeared to our outward sense or inward sentiment, the necessary conclusion seems to be that we have no idea of connexion or power at all, and that these words are absolutely without any meaning, when employed either in philosophical reasonings or common life. (Hume, 1777, p. 58)

Não há diferença significativa em pensarmos o regularismo como uma forma de realismo contingencialista ou como uma forma de anti-realismo contingencialista ${ }^{10}$. Se dissermos que não há leis,

Ainda que haja autores que não interpretem Hume como regularista, peço que o interpretemos aqui assim a fim de seguirmos o vocabulário padrão na metafísica das leis contemporânea (com o uso, por exemplo, do termo "visão de mundo humeana").

10 A diferença essencial é que um nega que existam leis e o outro aceita que elas existem. Essa diferença pode ser relevante para alguma área da Filosofia, mas não é relevante para o regularista, que pode aceitar tanto o antirealismo contingencialista, quanto o realismo contingencialista sem mudar nenhum aspecto essencial de sua teoria. Pois aceitar que leis existem e não têm nenhum tipo de necessidade faz com que o máximo que podemos chamar de "leis" sejam as regularidades humeanas, que são universais, condicionais,

Manuscrito - Rev. Int. Fil., Campinas, v. 36, n. 1, p. 67-101, jan.-jun. 2013. 
certamente não podemos estar querendo dizer que não há regularidades, pois é obviamente verdadeiro que há regularidades ${ }^{11}$. Quando negamos que há leis - quando somos anti-realistas - só podemos estar querendo negar que existam as leis dos realistas necessitaristas. Um anti-realista contingencialista pode aceitar tudo que um regularista aceita, inclusive que o único conceito concebível de leis naturais é o que as identifica com as regularidades, enquanto as únicas leis naturais que ele pode negar a existência são as leis dos realistas necessitaristas. Essa é exatamente a mesma atitude de quem nos diz que há leis e que elas não são nada mais que regularidades.

Tal como o regularismo é a união da tese anti-realista das leis (ou realista, já que regularismos realistas e anti-realistas não têm diferenças significativas) com a tese de que não há conexões necessárias na natureza, o substantivismo é a união da tese realista com a tese de que há conexões necessárias na natureza ${ }^{12}$. Ambas tentam nos dizer qual é a natureza de uma lei. Contrariamente ao regularista, o substantivista nos diz que as leis da natureza não são regularidades, elas são algo mais substantivo. De um modo geral, tal como os regularistas endossam o contingencialismo, os substantivistas endossam o necessitarismo. Os substantivistas estão de acordo com os regularistas quanto à suposição de que (Swartz, 2001, p. 2) as leis da natureza

verdadeiras e acidentais, coisa que quem crê que leis (tal como a necessidade não lógica) não existem também pode aceitar.

11 Repare que mesmo que não existam duas situações idênticas, haverá regularidades humeanas (verdades contingentes da forma $\forall \mathrm{x}(\mathrm{Fx} \rightarrow \mathrm{Gx})$ ), dado que será verdade que todo objeto que tem $F$ tem $G$, por mais que seja apenas um objeto particular.

12 O anti-realismo necessitarista de Mumford (2004) é chamado por nós de "conectivismo", já que sua teoria nos diz que há conexões necessárias na natureza, que não são leis. O conectivismo não é uma ontologia das leis, como seriam os substantivismos e o regularismo, mas é uma ontologia de como o mundo pode existir sem leis e com poderes, ou seja, o conectivismo é uma ontologia dos poderes.

Manuscrito - Rev. Int. Fil., Campinas, v. 36, n. 1, p. 67-101, jan.-jun. 2013. 
implicam conexões regulares entre estados de coisas ou propriedades que são expressas por proposições factuais universais, verdadeiras em todos os tempos e lugares do mundo, formuladas sem nomes próprios e transliteráveis para a forma condicional - eles concordam, por exemplo, que a lei de que os Fs são Gs implica que $\forall x$ ( $F x \rightarrow G x)$. Entretanto, eles rejeitam a suposição regularista fundamental segundo a qual as leis se reduziriam a tais conexões regulares observadas - e, assim, substantivistas rejeitam, por exemplo, que a lei de que os Fs são Gs se reduza a $\forall \mathrm{x}(\mathrm{Fx} \rightarrow \mathrm{Gx})$. Os substantivistas nos dizem que as leis da natureza são mais que as regularidades, que elas explicam as regularidades, que elas são conexões entre universais. Há duas formas de substantivismo, de acordo com a concepção de universal adotada. $\mathrm{O}$ substantivismo in rebus (propriedade aristotélica) nos diz que as leis da natureza são relações universais de necessitação entre propriedades universais, que dependem das e que estão nas coisas. E o substantivismo ante rem (propriedade platônica) nos diz que as leis da natureza são relações universais de necessitação entre propriedades universais, que existem independentemente das coisas que as instanciam.

Enfim, tendo apresentado as quatro maiores teorias com relação a leis naturais, passo a apresentar na próxima seção os Casos de Tooley, a fim de que possamos avaliar como essas teorias tentam solucioná-los.

\section{Os Casos de Tooley}

Nesta seção apresentaremos dois dos Casos de Tooley ${ }^{13}$ - o Caso da Partícula Fundamental e o Caso da Propriedade Emergente - e mostraremos qual a sua relevância para o nosso debate, a fim de que,

13 Há também um terceiro Caso de Tooley, chamado "Caso do Jardim de Smith", que, como não é um caso sobre leis não instanciadas, não será abordado neste artigo.

Manuscrito - Rev. Int. Fil., Campinas, v. 36, n. 1, p. 67-101, jan.-jun. 2013. 
posteriormente, avaliemos as tentativas de solução de cada uma das teorias apresentadas na introdução. Os casos são os seguintes.

- Caso da Partícula Fundamental (Tooley, 1977, p. 669):

Imagine um mundo que contém dez tipos diferentes de partículas fundamentais. Suponha, ademais, que o comportamento das partículas nas interações dependa dos tipos de partículas das interações. Considerando apenas as interações envolvendo duas partículas, há 55 possibilidades de tipos de interação entre duas partículas. Suponha que 54 dessas interações possíveis foram cuidadosamente estudadas, com o resultado de 54 leis terem sido descobertas, uma para cada caso, e nenhuma delas inter-relacionada com nenhuma outra. Suponha finalmente que o mundo é determinístico o suficiente para que, dado o modo como as partículas dos tipos $\mathrm{X}$ e $\mathrm{Y}$ estão correntemente distribuídas, seja impossível elas interagirem em qualquer tempo passado, presente ou futuro. Em tal situação, seria bastante razoável acreditar que há alguma lei não derivada que lida com a interação das partículas dos tipos X e Y.

- Caso da Propriedade Emergente (Tooley, 1977, p. 685):

Suponha que o materialismo é falso e que há, por exemplo, uma propriedade não física de ser uma experiência da variedade vermelha. Então, considere como o nosso mundo teria sido se a Terra estivesse um pouco mais próxima do sol e se as condições em outras partes do universo fossem tais que a vida não tivesse evoluído em mais nenhuma parte. $\mathrm{O}$ universo não teria contido nenhum organismo senciente e, consequentemente, não teria contido experiências da variedade vermelha. Mas não teria sido verdadeiro nesse mundo que se a Terra estivesse um pouco mais afastada do sol, a vida teria evoluído e haveria experiências da variedade vermelha? Se sim, em virtude de que tal condicional seria verdadeiro? Certamente uma parte essencial do seu veridador seria a existência de uma lei psicofísica, ligando estados físicos complexos à experiências da variedade vermelha. Mas se os veridadores de leis são as relações entre universais, então, a não ser que a propriedade de ser uma experiência da variedade vermelha exista em tal mundo, não poderia ser uma lei que sempre que um sistema físico

Manuscrito - Rev. Int. Fil., Campinas, v. 36, n. 1, p. 67-101, jan.-jun. 2013. 
complexo está num certo estado, há uma experiência da variedade vermelha. ${ }^{14}$

O que é interessante de ambos esses casos é que eles nos mostram situações em que estaríamos tentados a postular leis não derivadas e não instanciadas. A razão pela qual Tooley (1977) pensa ser importante fornecer uma abordagem para esses casos é que eles são logicamente possíveis; e, se assim forem, mostram que as leis não instanciadas não são uma impossibilidade lógica. $\mathrm{E}$ isso seria relevante na medida em que as objeções contra as leis não instanciadas, diz-nos Tooley, tentariam mostrar que leis não instanciadas são logicamente impossíveis.

Contudo, sem negar as razões de Tooley, é possível tomar tais casos como importantes por outro motivo completamente diferente. Tal motivo seria que tais casos não são estados de coisas apenas meramente possíveis. Os Casos de Tooley nos mostram duas situações possíveis que são análogas a situações que atualmente vivemos. Por exemplo, o Caso da Partícula Fundamental nos fala de uma situação possível em que há 55 tipos de interações possíveis de duas partículas, e 54 delas são leis conhecidas. Nessa situação seria racional postular a existência de uma lei ainda desconhecida para nós. E se esse 55o tipo de interação nunca ocorresse no mundo, embora fosse possível de ocorrer, além de uma lei não conhecida, seria também uma lei não instanciada. A situação análoga a essa seria a situação que atualmente nos encontramos de não sabermos quais são todas as interações possíveis

14 Podemos reformular o Caso da Propriedade Emergente sem pressupor a falsidade do materialismo. Os poderes, tais como as propriedades emergentes, surgem (em algum sentido adequado de "surgem") e dependem das estruturas (particular com propriedades categóricas) das quais eles são poderes. Nesse sentido, podemos falar sobre o caso em que se o mundo fosse tal que nenhuma estrutura tivesse surgido, mesmo assim seria verdadeiro que se houvesse uma estrutura do tipo X, ela teria o poder do tipo Y. E o que faria tal contrafactual verdadeiro só poderia ser uma lei da natureza ante rem - nos diria Tooley.

Manuscrito - Rev. Int. Fil., Campinas, v. 36, n. 1, p. 67-101, jan.-jun. 2013. 
entre os diversos tipos de partículas e de tentarmos descobrir as leis que regem essas interações. Se é racional pensarmos que há uma lei por descobrir mesmo no caso de não sabermos se a interação regida por tal lei acontece em algum instante do tempo, então seria racional pensarmos que há uma lei por descobrir mesmo no caso da interação regida por tal lei não acontecer em nenhum instante do tempo.

Esse foi um argumento epistêmico, mas temos outras razões mais metafísicas. Por exemplo, as fórmulas que nos dizem quais propriedades precisamos juntar para conseguirmos o efeito de uma certa bomba (atômica, nêutrons, etc). Pode ser que todos os governos lutem contra as pessoas juntarem as condições para instanciarem tal efeito, fazendo com que tal efeito (que seria a condição consequente da lei) nunca fosse instanciado. Isso certamente só poderia ocorrer se essas pessoas acreditassem que há uma lei não instanciada que eles temem instanciar. Mas eles só podem temer a instanciação da lei se antes acreditarem que há lei (que pode ou não já ter sido instanciada anteriormente ou futuramente no mundo).

O outro caso, o da Propriedade Emergente, também nos mostra uma situação em que gostaríamos de postular leis não instanciadas e não derivadas. Pois mostra uma situação em que apenas leis não instanciadas poderiam ser os veridadores dos condicionais contrafactuais que são verdadeiros em tais situações. $O$ caso fala de contrafactuais em outros mundos; e, consequentemente, nos faz pensar que tal caso é apenas uma mera possibilidade. No entanto, há planetas que estão atualmente na posição em que supomos que o planeta Terra do mundo alternativo do Caso da Propriedade Emergente estaria. E, nesse sentido, o condicional contrafactual "se Mercúrio estivesse um pouco afastado do sol, haveria vida consciente nele" é verdadeiro. E isso seria verdadeiro, mesmo que não existisse (e quando não existia) a Terra e seus terráqueos com vida consciente. E, se atualmente, quando há terráqueos com vida consciente, dizemos que é uma certa lei que 
conecta algumas condições ambientais e as propriedades de Mercúrio ${ }^{15}$ com a vida consciente, não podemos dizer que não seria essa mesma lei que faria verdadeiro o mesmo condicional, caso não houvesse o planeta Terra. E, se houvesse tal lei, ela seria uma lei não instanciada, já que versaria sobre a vida consciente - algo que não estaria instanciado, caso não houvesse Terra.

Mas como tais casos se relacionam com a nossa escolha de uma teoria das leis naturais? Seja se quisermos rejeitar, seja se quisermos aceitar a existência de leis naturais, parecer-nos-á que teremos que fornecer uma abordagem para os Casos de Tooley, uma abordagem para quais seriam os veridadores dos contrafactuais relevantes em tais casos. E teremos, porque, além de casos possíveis, tais casos são análogos a situações actuais; e uma teoria das leis da natureza que não é capaz de explicar nem os casos possíveis e nem os casos actuais certamente não é uma boa teoria das leis. Porque uma boa teoria das leis naturais deve fornecer às leis características que leis científicas verdadeiras teriam; e as leis científicas são tais que, se forem verdadeiras, farão verdadeiros os contrafactuais relevantes.

\section{O Conectivismo e os Casos de Tooley}

O conectivismo nos diz que há conexões necessárias na natureza, porém, nega que essas conexões sejam leis. Para um conectivista, essas conexões estão nas propriedades das coisas, que por serem essencialmente poderes (propriedades disposicionais), estabelecem conexões necessárias entre estímulos e manifestações. Em termos formais, sua necessidade se expressa apenas nas relações entre particulares, como $\mathrm{N}(\mathrm{Fa}, \mathrm{Ga})$, e nunca em relações entre universais,

15

Aqui vale notar que as leis conectam apenas condições ambientais gerais, que existem em Mercúrio, como o surgimento de vida consciente, e nunca conectam condições particulares com relação especificamente ao planeta Mercúrio ou ao planeta Terra.

Manuscrito - Rev. Int. Fil., Campinas, v. 36, n. 1, p. 67-101, jan.-jun. 2013. 
como $\mathrm{N}(\mathrm{F}, \mathrm{G})$. E, além disso, sua relação de necessitação necessária ${ }^{16}$ é interna às propriedades (no caso, $F$ e $G$ ) e as conecta em função da natureza, da essência, da identidade da própria propriedade.

Um exemplo de conectivista é Stephen Mumford (2004). Tal filósofo pensa que há algo de errado em acreditarmos que há leis naturais. "Lei natural" seria antes uma metáfora enganadora para falar de certas características modais do mundo do que a descrição de um fato. Ele diria que as leis são uma solução para um problema advindo de uma concepção de mundo humeana, que nos diz que o mundo é composto de objetos discretos, não conectados e não animados. No entanto, ele pensa que podemos aceitar uma visão de mundo em que os particulares não são coisas inertes que precisam de animação por leis, mas que são intrinsecamente ativos. Sua visão é a de que, como as propriedades são essencialmente poderes (ou feixes de poderes), os particulares que têm as propriedades são intrinsecamente ativos porque possuírem tais propriedades.

Pode o conectivismo fornecer uma solução para os Casos de Tooley? Como vimos, em ambos os casos nos perguntamos sobre os veridadores de certos condicionais subjuntivos. No Caso da Partícula Fundamental, o contrafactual é "se partículas dos tipos X e Y tivessem interagido, o resultado teria sido W" e, no Caso da Propriedade Emergente, o contrafactual relevante é "se as propriedades F e G

16 A necessitação necessária se contrapõe ao conceito armstronguiano de necessitação contingente, que é uma relação que se mantém no mundo atual por alguma força maior que a contingência, mas que não se mantém em todos os mundos possíveis. A necessitação necessária se mantém em todos os mundos, seja em todos os mundos em que existe aquilo sobre o qual ela versa (necessitação fracamente necessária), ou seja em todos os mundos possíveis sem mais restrições (necessitação fortemente necessária). Enquanto a necessitação contingente preserva a intuição de que as leis poderiam ter sido outras e torna confusa a explicação dos contrafactuais, a necessitação necessária torna mais claro este último ponto, mas faz com que as leis não pudessem ter sido outras.

Manuscrito - Rev. Int. Fil., Campinas, v. 36, n. 1, p. 67-101, jan.-jun. 2013. 
tivessem entrado em contato, elas fariam emergir a propriedade H”. A solução do problema levantado pelos Casos de Tooley envolve dizer quais são os veridadores desses condicionais subjuntivos, ou, caso eles sejam falsos, envolve dizer qual a razão pela qual eles são falsos.

Um primeiro problema que esses casos apresentam ao conectivismo é a sua universalidade. O conectivismo postula um mundo de particulares com poderes universais, mas as leis dos Casos de Tooley não versam apenas sobre particulares com poderes universais, mas também sobre casos de universais sem instâncias e sobre instâncias meramente possíveis ${ }^{17}$. Tudo que o conectivista pode dizer é que as partículas que existem atualmente têm certos poderes, e não que qualquer partícula pertencente ao mesmo tipo, seja ela atual ou meramente possível, teria o mesmo poder. E não pode dizer tal coisa, pois se sua metafísica nos fala apenas dos particulares existentes e seus poderes, ela não pode concluir nada sobre os particulares não atualmente existentes, mas possivelmente existentes. Essa objeção é relevante na medida em que as leis científicas nos permitiriam falar sobre entidades meramente possíveis, e as leis conectivistas (reduzidas aos poderes das coisas) não permitem.

Outra objeção ao conectivismo, no mesmo espírito da objeção anterior, é que a dependência dos poderes com relação aos seus portadores particulares faz com que os poderes deixem de existir assim que seus portadores deixam de existir. E o problema disso é que não gostaríamos que os condicionais subjuntivos que seriam feitos

17 Por exemplo, o Caso da Partícula Fundamental nos fala sobre quaisquer partículas de certos tipos, incluindo as meramente possíveis, e não apenas das partículas atualmente existentes. E o Caso da Propriedade Emergente, além de ter o mesmo problema acima, nos fala sobre uma propriedade não instanciada (a de ter uma mente consciente) num certo mundo, de modo que não poderia estar falando de nenhum particular que tem tal propriedade ou que tem uma disposição para ter tal propriedade - já que não haveria humanos (ou seres análogos) no mundo de tal caso - mas teria de falar do universal.

Manuscrito - Rev. Int. Fil., Campinas, v. 36, n. 1, p. 67-101, jan.-jun. 2013. 
verdadeiros pelas leis dos Casos de Tooley deixassem de ser verdadeiros apenas porque os particulares que tinham os poderes relevantes para a lei deixaram de existir. Um condicional subjuntivo que seria feito verdadeiro por uma lei científica verdadeira é algo intemporalmente verdadeiro, ou seja, algo que não deixa de ser verdadeiro. E, portanto, não poderia ser feito verdadeiro por algo que não se encontre em todo o tempo. Uma lei se encontra em todo o tempo, mas como o conectivista rejeita a existência de leis, ele só pode apelar aos poderes dos particulares, que por sua vez não existem em todo o tempo, dado que os próprios particulares não existem em todo o tempo. ${ }^{18}$

Todavia, é argumentável que há um certo tipo de particular que existiria em todo o tempo, a saber, os átomos metafísicos. Átomos metafísicos seriam particulares indivisíveis que formariam toda a matéria ${ }^{19}$. Um conectivista poderia dizer que um particular só deixa de existir quando se transforma em outro particular, e que isso só é possível por algum tipo de combinação das partes do particular em causa. Assim, se existirem átomos metafísicos, por serem indivisíveis ${ }^{20}$,

18

O que é desvantajoso é que enquanto o conectivista não puder mostrar quais são os veridadores dos condicionais subjuntivos relevantes, não poderá nos explicar uma característica central das leis científicas, que é a sua contrafactualidade. A conexão aqui entre leis naturais e leis científicas é que se as disposições dos particulares não puderem dar conta da contrafactualidade que as leis naturais dariam conta, então não poderão dar conta da contrafactualidade de qualquer lei científica, dado que as leis científicas são um espelho das leis naturais, no que diz respeito às propriedades formais. E os conectivistas, tal como Bird (2007) e Ellis (2009), são conhecidos por tentarem fornecer uma metafísica das ciências.

19 Veja uma discussão sobre a formação da matéria por átomos metafísicos (ou átomos filosóficos, tal como chamados por alguns) e por contínuos, e veja também um pouco sobre o dilema da continuidade da matéria em Cid (2011).

20 Os átomos metafísicos seriam conceitualmente indivisíveis, e não apenas praticamente indivisíveis. Ou seja, não é o fato de não termos os meios para dividi-los que os torna indivisíveis, mas é antes o fato de eles serem

Manuscrito - Rev. Int. Fil., Campinas, v. 36, n. 1, p. 67-101, jan.-jun. 2013. 
eles não serão formados de partes. E, consequentemente, não poderiam deixar de existir - se deixar de existir for realmente, como propõe o conectivista, apenas certo tipo de modificação nas relações das partes. Se esse for o caso, então o conectivista poderia salvaguardar algumas disposições que existiriam em todo o tempo, a saber, as disposições dos átomos metafísicos.

Mas poderão as disposições dos átomos metafísicos ${ }^{21}$ dar conta de todos os condicionais subjuntivos verdadeiros? Como eu disse anteriormente, há um problema sério em particulares conseguirem dar conta da universalidade de uma lei. Haverá condicionais subjuntivos que nos dirão que certa interação entre dois átomos metafísicos quaisquer terão um certo resultado. E, como tais condicionais dizem respeito a qualquer átomo metafísico (seja atual ou meramente possível), eles não poderão ser feitos verdadeiros por disposições dos objetos particulares actuais e nem pela conjunção dessas disposições.

No entanto, suponhamos que o problema da universalidade possa ser resolvido (coisa que eu não acho possível). O conectivista poderia tentar dizer que as partículas do tipo $\mathrm{X}$ têm o poder de

indivisíveis que faz ser impossível de criarmos um meio para dividi-los. A indivisibilidade conceitual é exigida, além da indivisibilidade prática, pois se algo fosse praticamente indivisível e conceitualmente divisível, então esse algo não serviria ao papel de explicar a continuidade daquilo que ocupa o espaço. E é justamente para fornecer essa explicação - entre outras - que postulamos átomos metafísicos.

21 Uma observação que devemos fazer aqui é que se começarmos a falar de átomos metafísicos, teremos que pensar o Caso da Partícula Fundamental como um caso em que há tipos diferentes de interação entre o mesmo tipo de partícula, já que se houvesse átomos metafísicos, eles seriam o tipo mais fundamental de partícula. E seria possível dizer que a diferença de tipos de partículas existe apenas na medida em que o mesmo tipo de partícula fundamental (os átomos metafísicos) se organiza diferentemente. 
manifestar $\mathrm{F}$ quando interagem com as partículas do tipo $\mathrm{Y}^{22}$ e que as partículas do tipo $\mathrm{Y}$ têm o poder de manifestar $\mathrm{F}$ quando interagem com as partículas do tipo $\mathrm{X}$, e que não há nada mais para a lei de que $\mathrm{XY}$ manifesta $\mathrm{F}$ do que esses poderes de $\mathrm{X}$ e de $\mathrm{Y}$. O problema de dizer tal coisa é que a manifestação de F estaria sobredeterminada, já que ambas as partículas fariam F ser manifestado. Poderíamos tentar solucionar tal problema dizendo que as partículas do tipo $\mathrm{X}$ têm $\mathrm{O}$ poder de manifestar $\mathrm{F}^{1}$ quando interagem com as partículas do tipo $\mathrm{Y}$, que as partículas do tipo $\mathrm{Y}$ têm o poder de manifestar $\mathrm{F}^{2}$ quando interagem com as partículas do tipo $\mathrm{X}$, e que $\left(\mathrm{F}^{1} \wedge \mathrm{F}^{2}\right) \rightarrow \mathrm{F}$.

Poderíamos objetar a essa resposta, dizendo que teríamos que explicar, então, como $\left(\mathrm{F}^{1} \wedge \mathrm{F}^{2}\right) \rightarrow \mathrm{F}$; e o conectivista não é capaz de explicar isso sem cair no problema da sobredeterminação ou num regresso ao infinito: se $\left(\mathrm{F}^{1} \wedge \mathrm{F}^{2}\right) \rightarrow \mathrm{F}$, então (i) ou $\mathrm{F}^{1}$ está disposto a manifestar $\mathrm{F}$ quando estimulado por $\mathrm{F}^{2}$, e $\mathrm{F}^{2}$ está disposto a manifestar $\mathrm{F}$ quando estimulado por $\mathrm{F}^{1}$; (ii) ou $\mathrm{F}^{1}$ está disposto a manifestar $\mathrm{F}^{3}$ quando estimulado por $\mathrm{F}^{2}, \mathrm{~F}^{2}$ está disposto a manifestar $\mathrm{F}^{4}$ quando estimulado por $\mathrm{F}^{1}$, e $\left(\mathrm{F}^{3} \wedge \mathrm{F}^{4}\right) \rightarrow \mathrm{F}$. O caso (i) faria $\mathrm{F}$ estar sobredeterminado. E, no caso (ii), o problema seria ter que explicar a implicação de $\mathrm{F}^{3} \wedge \mathrm{F}^{4}$ para $\mathrm{F}$, que nos parece apenas ser possível criando um caso como (i), que sobredeterminaria F, ou criando um outro caso como (ii) ad infinitum.

Se o conectivismo tem realmente os problemas aqui apresentados, eles o tornariam incapaz de fornecer uma abordagem satisfatória para os Casos de Tooley.

22 Ou, alternativamente, no caso do defensor dos átomos metafísicos, quando duas partículas do tipo $\mathrm{X}$ (do tipo átomo metafísico) interagem do modo $\mathrm{Y}$, elas produzem $\mathrm{F}$.

Manuscrito - Rev. Int. Fil., Campinas, v. 36, n. 1, p. 67-101, jan.-jun. 2013. 


\section{O Regularismo e os Casos de Tooley}

O Regularismo, pelo menos em sua forma ingênua, é a teoria que nos diz que as leis da natureza não passam de quantificações universais condicionais intemporalmente verdadeiras com predicados empíricos não locais e com a forma " $\forall \mathrm{x}(\mathrm{Fx} \rightarrow \mathrm{Gx})$ ", ou seja, que as leis da natureza não passam de regularidades humeanas. ${ }^{23}$

Qual é o problema que os Casos de Tooley colocam em cena para o regularismo? O regularismo é uma teoria que nos diz que o que realmente existe ou são particulares, ou sobrevêm a eles, ou seja, é uma teoria que aceita a sobreveniência humeana. ${ }^{24}$ Os Casos de Tooley indicariam situações em que a sobreveniência humeana não se mantém, pois seriam casos de leis que existem independentemente de suas instâncias particulares. Se o regularismo não puder fornecer uma abordagem teórica para quais são os veridadores dos contrafactuais de tais casos, isso atestará fatalmente contra a teoria, pois tais casos têm análogos actuais. E, assim, a falha em fornecer uma abordagem para eles seria, então, também uma falha em fornecer uma abordagem para certos casos actuais.

Armstrong (1983, pp. 19-20) nos fornece algumas razões pelas quais o regularismo não pode fornecer uma abordagem plausível para

23 Por sua vez, o regularista sofisticado tende a ser mais específico e nos diz que p é um enunciado de uma lei da natureza se e só se exprimir um tipo de regularidade humeana. A principal distinção entre os diferentes regularismos sofisticados é no tipo de regularidade humeana que eles identificam com as leis. David Lewis (1973), por exemplo, nos diz que as leis da natureza são apenas as regularidades humeanas que são teoremas ou axiomas nos sistemas dedutivos com a melhor combinação de simplicidade e força.

$24 \quad$ O sentido de "tudo que existe são particulares e todo o mais sobrevêm a eles", no caso do regularismo, é uma versão forte da superveniência humeana, que nos diz que tudo que sobrevêm aos particulares e não é particular não existe, ou seja, só há particulares e composições a partir de particulares. Não há nada que não seja particular.

Manuscrito - Rev. Int. Fil., Campinas, v. 36, n. 1, p. 67-101, jan.-jun. 2013. 
os Casos de Tooley. Armstrong nos diz que o regularismo tem um problema geral com leis não instanciadas: se aceitamos que $\forall \mathrm{x}$ $(\mathrm{Fx} \rightarrow \mathrm{Gx})$ é uma lei, então haverá casos em que $\mathrm{F}$ não é instanciado, em que teremos que aceitar que leis contraditórias são o caso. Comecemos do princípio. Um condicional material é verdadeiro quando ambos antecedente e consequente são verdadeiros ou quando a antecedente é falsa. Assim, " $\forall \mathrm{x}(\mathrm{Fx} \rightarrow \mathrm{Gx})$ " seria trivialmente verdadeiro quando " $\forall \mathrm{x}$ $\sim F x$ ” fosse verdadeiro, dado que quando $F$ é vazio, tal condicional é vacuamente verdadeira. E uma condicional material é falsa quando sua antecedente é verdadeira e sua consequente é falsa. Por exemplo: "se x é homem, então x é mortal” é falsa se houver algo que seja um homem e não seja mortal. E no caso de não haver homens, ela seria verdadeira. Ou seja, "se x é F, então x é G" é falsa apenas se houver algo que é F e não é G. Em todos os outros casos, incluindo o caso de não haver Fs, "se x é F, então x é G" não seria falsa (já que sua falsidade exigiria a existência de um indivíduo que é $F$ e não é $G$ ) e seria, portanto, verdadeira. Entretanto, é aqui que as coisas se complicam, pois o que impediria " $\forall \mathrm{x}(\mathrm{Fx} \rightarrow \sim \mathrm{Gx})$ " de ser verdadeiro no caso de não haver Fs? Armstrong nos diz que o regularista não tem recursos para impedir a si mesmo, na ausência de Fs, de contar ambas " $\forall \mathrm{x}(\mathrm{Fx} \rightarrow \mathrm{Gx})$ " e " $\forall \mathrm{x}(\mathrm{Fx} \rightarrow \sim \mathrm{Gx})$ " como leis, já que, por não haver Fs, não há um $\mathrm{F}$ que não seja $G$ (que faria “ $\forall x(F x \rightarrow G x)$ " ser falsa) e nem há um $F$ que seja $\mathrm{G}$ (que faria " $\forall \mathrm{x}(\mathrm{Fx} \rightarrow \sim \mathrm{Gx})$ " ser falsa). ${ }^{25}$

25 Poderíamos pensar que a teoria dos mundos possíveis de David Lewis (1986) fosse ajudar neste caso. Mas tal teoria só poderia ajudar se o regularista tomasse as leis como " $\square \forall \mathrm{x} \quad(\mathrm{Fx} \rightarrow \mathrm{Gx})$ ", e não como " $\forall \mathrm{x}(\mathrm{Fx} \rightarrow \mathrm{Gx}) "$. Pois nesse caso, poderíamos dizer que a lei é verdadeira quando todas as instâncias de Fs em todos os mundos possíveis são também Gs. Mas as leis do regularista diferem em cada mundo possível, sendo por sua vez contingentes. $\forall \mathrm{x}(\mathrm{Fx} \rightarrow \mathrm{Gx})$ é uma lei no mundo atual, e não é uma lei em alguns outros mundos possíveis. Por isso, o regularista não pode dizer que

Manuscrito - Rev. Int. Fil., Campinas, v. 36, n. 1, p. 67-101, jan.-jun. 2013. 
Uma das respostas a esse problema é dizer que se há alguma propriedade intemporalmente não instanciada, então $\forall \mathrm{x} \sim$ Fx seria uma regularidade humeana e, portanto, sob a perspectiva do regularista ingênuo, seria também uma lei. $\mathrm{E}$ se $\forall \mathrm{x} \sim \mathrm{Fx}$ é uma lei, a existência de Fs não ocorre. No entanto, como não há leis sobre propriedades que não são instanciadas, segundo o regularismo, não há lei alguma sobre Fs, no caso de intemporalmente não haver Fs. Essa resposta é estranha na medida em que $\forall \mathrm{x} \sim F_{x}$ é equivalente a $\sim \exists x$ Fx e que $\sim \exists x$ Fx diz respeito a $F$ s, e na medida que remove a capacidade do regularismo de dizer que " $\forall \mathrm{x} \sim \mathrm{Fx}$ " é uma lei.

No entanto, há uma outra saída para o regularista, a saber, modificar a forma da regularidade que será considerada lei, exigindo um importe existencial. Por exemplo (Armstrong, 1983, p. 20), pode-se tentar trocar " $\forall \mathrm{x}(\mathrm{Fx} \rightarrow \mathrm{Gx})$ " por " $\exists \mathrm{x}(\mathrm{Fx}) \wedge \forall \mathrm{x}(\mathrm{Fx} \rightarrow \mathrm{Gx})$ ", o que faria não haver lei no caso de não haver Fs. Isso faria com que o regularista não tenha que dizer que há a suposta lei não instanciada do Caso da Partícula Fundamental, pois em tal caso não existiria a condição antecedente da lei, condição esta exigida pelo novo critério do regularista para haver uma lei.

Porém, ao menos um problema não é resolvido por esta resposta, a saber, o Caso da Propriedade Emergente, que é um caso em que a consequente da lei não está instanciada. Para resolver tal caso, o regularista poderia novamente tentar uma nova formulação da lei, tal como " $\exists \mathrm{x}(\mathrm{Fx}) \wedge \exists \mathrm{x}(\mathrm{Gx}) \wedge \forall \mathrm{x}(\mathrm{Fx} \rightarrow \mathrm{Gx})$ ". Isso faria com que não houvesse lei nem no Caso da Partícula Fundamental e nem no Caso da Propriedade Emergente. Mas não seria capaz de responder a questão central dos Casos de Tooley, que é saber qual é o veridador dos contrafactuais relevantes nesses casos. ${ }^{26}$

" $\forall \mathrm{x}(\mathrm{Fx} \rightarrow \mathrm{Gx})$ " é verdade no mundo atual em virtude de fatos com relação a outros mundos possíveis.

26 Relembrando: no Caso da Partícula Fundamental, o contrafactual "se partículas de tipos X e Y tivessem interagido, o resultado teria sido W" seria

Manuscrito - Rev. Int. Fil., Campinas, v. 36, n. 1, p. 67-101, jan.-jun. 2013. 
O regularismo tem um problema geral com contrafactuais, pois, como suas leis não têm necessidade alguma, também não têm força contrafactual alguma. Toda necessidade e contrafactualidade é determinada por leis lógicas para o regularista. ${ }^{27}$ Assim, ele estaria comprometido a falar que os contrafactuais dos Casos de Tooley não são verdadeiros. O problema de o regularista falar tal coisa é que isso seria contra a sua própria motivação de dar conta também das leis científicas, que têm certa força contrafactual. Os cientistas, por tentarem descobrir leis, sempre pressupõem que nos casos como os de Tooley haveria certos contrafactuais que seriam verdadeiros. E o regularismo não pode explicar satisfatoriamente - ou seja, preservando sua compatibilidade com as ciências - os Casos de Tooley.

\section{O Substantivismo In Rebus e os Casos de Tooley}

O Substantivismo In Rebus, tal como exemplificado pela teoria realista de David Armstrong (1983), é a posição metafísica que nos diz que as leis da natureza realmente existem e são relações de necessitação ${ }^{28}$ entre universais e que os universais são atributos

verdadeiro e, no Caso da Propriedade Emergente, o contrafactual "se as propriedades $F$ e $G$ tivessem entrado em contato, elas fariam emergir a propriedade H" seria verdadeiro. Estes seriam os contrafactuais para os quais Tooley procura os veridadores.

27 E geralmente, tal como faz o conhecido regularista David Lewis (1986), até mesmo essa necessidade lógica é reduzida à verdade em todos os mundos [logicamente] possíveis.

28 Ou, no caso de existirem leis probabilísticas, Armstrong diria (1983, pp. 128-136) que a relação entre os universais seria a relação de probabilificação, que é a probabilidade que os universais têm de um necessitar o outro. E a relação de necessitação seria apenas o caso limite de 100\% de probabilificação. E sua necessitação contingente seria uma relação que garante a regularidade no mundo atual, mas não garante em outros. No entanto, é possível para o substantivista defender qualquer tipo de relação de necessitação entre universais, seja ela a necessitação contingente (que garante a regularidade no Manuscrito - Rev. Int. Fil., Campinas, v. 36, n. 1, p. 67-101, jan.-jun. 2013. 
instanciáveis e abstraíveis dos estados de coisas actuais. Ou seja, a partir dos estados de coisas Fa, Fb, Fc etc, abstraímos F, e a partir dos estados de coisas Ga, Gb, Gc, abstraímos G. E a partir de Fa causando Ga, Fb causando Gb, Fe causando Ge, abstraímos a lei N(F,G), em que "N" representa a relação de necessitação contingente 29 que os universais $F$ e $G$ estabelecem entre si. É apenas porque há essa necessitação contingente entre os universais que cada uma e todas as sequências causais em que Fx causa Gx ocorrem. A ideia de Armstrong é que apenas conseguimos abstrair $\mathrm{F}$ dos estados de coisa em que há $\mathrm{F}$, pois há F em tais estados de coisas. Os universais de Armstrong são pensados como as características repetíveis do mundo, como aquilo que é o mesmo em cada uma das instâncias ${ }^{30}$, tomando o mundo como um bloco espaço-temporal. E por isso sua teoria também nos diz que todos os universais seguem o Princípio da Instanciação (1983, p. 82) - PI ${ }^{31}$ :

Os universais são governados por um Princípio de Instanciação. Uma propriedade deve ser uma propriedade de um particular real; uma relação deve ser uma relação entre particulares reais. O que é real,

mundo atual), seja a necessitação fracamente necessária (que garante a regularidade em todos os mundos em que há instâncias da lei). A necessitação fortemente necessária (que garante a regularidade em todos os mundos possíveis, mesmo naqueles em que não há instâncias da lei) só pode ser defendida pelo substantivista ante rem.

29 Relação esta que apenas garante a relação entre as instâncias dos universais no mundo atual serem conforme a lei, ou seja garante a regularidade. Esta relação é pensada (por exemplo, por David Armstrong, 1983) como distinta da extrema contingência, que não garante nada no mundo atual, e das relações de necessidade forte e fraca, as quais já explicamos na nota anterior.

30 Armstrong (1983, p. 83), ao utilizar essa definição, pensa ter já excluído de bom grado de sua ontologia os universais disjuntivos e negativos. 31 Junto com PI, Armstrong aceita também o Princípio da Rejeição dos Particulares Puros, que nos diz que todo particular tem propriedades. Não me parece relevante discutir aqui a adequação desse princípio; e, por esta razão, restrinjo-me a falar dele numa nota de rodapé, deixando o texto básico para a discussão do PI. E Armstrong aceita também que o mundo é formado de estados de coisas.

Manuscrito - Rev. Int. Fil., Campinas, v. 36, n. 1, p. 67-101, jan.-jun. 2013. 
entretanto, não deve ser confinado ao presente. Eu tomo o passado, o presente e o futuro como igualmente reais. Um universal não precisa estar instanciado agora.

O problema que os Casos de Tooley trazem à teoria de Armstrong advém da aceitação do Princípio de Instanciação. Se todos os universais obedecem ao PI - e, consequentemente, se não há leis universais não instanciadas - então o que faria verdadeiros os condicionais subjuntivos dos Casos de Tooley? Armstrong (1983, pp. 117-127) mesmo nota o problema que esses casos representam para sua teoria e tenta fornecer uma abordagem para tais casos em termos de leis de segunda ordem que fazem verdadeiros alguns contrafactuais sobre a existência de leis de primeira ordem, tal como veremos a seguir.

Os Casos de Tooley nos mostram situações possíveis em que seria racional aceitarmos que há leis sobre universais não instanciados. Um substantivista in rebus deve estar apto a nos mostrar que essas não são leis não instanciadas, já que ele não crê que algo não instanciado seja uma propriedade universal. Ele deveria nos mostrar como cada suposta lei não instanciada pode ser reduzida a uma lei instanciada.

Armstrong tenta fazer isso (1983, p. 119), nos dizendo que, com relação ao Caso da Partícula Fundamental, é verdadeiro o seguinte contrafactual: se a interação X-Y existisse, embora de fato não exista, então existiria uma relação de necessitação entre tal interação universal e outro universal [instanciado]. E tal contrafactual seria feito verdadeiro por uma lei de ordem superior que determina a lei de ordem inferior. Armstrong (1983, pp. 123-124) nos diz que essa lei de ordem superior seria semelhante a: é uma lei [de segunda ordem] sobre as leis [de primeira ordem] de interação fundamental que, dados dois tipos diferentes de interação, qualquer lei [de primeira ordem] que governe um tipo de interação será diferente da lei [de primeira ordem] que governa outro tipo de interação.

E, com relação ao Caso da Propriedade Emergente, Armstrong (1983, p. 124) faz o mesmo, nos dizendo que é verdadeiro o Manuscrito - Rev. Int. Fil., Campinas, v. 36, n. 1, p. 67-101, jan.-jun. 2013. 
contrafactual que nos diz que: se os universais em jogo estivessem instanciados, embora não estejam, existiria uma certa lei entre eles. E tal contrafactual seria feito verdadeiro por uma lei de ordem superior. Tal lei seria semelhante a: é uma lei [de segunda ordem] com relação a um certo domínio complexo de propriedades que se os objetos têm um certo tipo de conjunção de propriedades desse domínio, então é uma lei [de primeira ordem] que eles têm certas propriedades emergentes simples, com uma propriedade diferente sendo associada com cada conjunção diferente.

O que podemos dizer dessa solução? O problema dela é que a partir de tais tipos de leis de ordem superior não é possível deduzir logicamente as leis de ordem inferior que gostaríamos - tal como somos capazes de deduzir cada um dos valores resultado de uma certa função ao termos o valor da lei funcional de segunda ordem que rege a atribuição de valores. Armstrong é capaz apenas de deduzir a partir das leis de ordem superior que as leis de ordem inferior para cada tipo de interação de duas partículas são diferentes (idiossincráticas), e não que há uma certa lei de ordem inferior específica que governa as propriedades não instanciadas envolvidas de uma certa forma. Sua dedução certamente nos permite dizer que uma lei existiria, caso estivessem instanciadas as propriedades, mas não qual lei seria essa. A lei de segunda ordem de Armstrong seria o veridador do contrafactual que o próprio Armstrong indicou - "se os universais em jogo estivessem instanciados, embora não estejam, existiria uma certa lei entre eles" - , mas não teria como ser o veridador dos contrafactuais dos Casos de Tooley. O que deveria ser deduzido da lei de ordem superior, a fim de que o contrafactual em causa tenha um veridador, é a própria lei de ordem inferior, e não o fato de que haveria uma lei de ordem inferior, caso as propriedades em causa estivessem instanciadas. Além disso, como as leis de Armstrong dependem ontologicamente de suas instâncias, elas não podem explicar como as instâncias chegam a 
ser instanciadas. E são por ambas essas razões que devemos rejeitar a solução de Armstrong.

\section{O Subtantivismo Ante Rem e os Casos de Tooley}

O substantivismo ante rem é a posição metafísica que nos diz que as leis realmente existem e que elas são relações de necessitação (ou algo semelhante, como as funções de construção de Tooley) entre universais transcendentes, ou seja, relações entre universais que existem independentemente das coisas que os instanciam. A maior expressão antiga dessa posição foi Platão e sua teoria das ideias. E a maior expressão contemporânea dessa posição é o filósofo Michael Tooley (1977). Ao investigar as condições de verdade dos enunciados de leis, Tooley sustenta que os seus veridadores são as relações contingentes entre os universais e que esses universais existem independentemente dos particulares. Sua teoria, tal como a de Armstrong (1983), nos fala de relações contingentes entre universais explicando as regularidades. É apenas porque $F$ e $G$ têm uma certa relação nômica de necessitação contingente que é verdade que $\forall x(F x \rightarrow G x)$. Tal relação nômica entre os universais $F$ e $G$ implicaria logicamente que $\forall x(F x \rightarrow G x)$, já que todas as instâncias dos universais em causa no nosso mundo compartilhariam das relações que os universais têm.

Contudo, Armstrong e Tooley também têm suas diferenças. Tooley (1977, pp. 678-679), por exemplo, em vez de utilizar a relação de necessitação, tentou desenvolver sua teoria com o conceito de função de construção [construction function]:

$\mathrm{R}$ é uma relação nomológica sse $\mathrm{s}^{32}$

(1) R é uma relação n-ádica entre universais;

(2) R não é analisável em termos de outros universais de qualquer ordem;

32 Nesta citação, (2) já está devidamente substituída pela proposição que Tooley (1977, p. 680) pensa ser menos problemática que a original.

Manuscrito - Rev. Int. Fil., Campinas, v. 36, n. 1, p. 67-101, jan.-jun. 2013. 
(3) R é uma relação contingente entre universais, no sentido em que há os universais $\mathrm{U} 1, \mathrm{U} 2, \ldots$, Un, e nem é necessário que $\mathrm{R}(\mathrm{U} 1, \mathrm{U} 2, \ldots$, $\mathrm{Un})$, nem é necessário que não $\mathrm{R}(\mathrm{U} 1, \mathrm{U} 2, \ldots, \mathrm{Un})$;

(4) há uma função de construção $K$, tal que (i) se P1, P2, ... Pn são propriedades ou relações dos tipos apropriados, então K(P1, P2, .., Pn) é uma proposição sobre particulares, e (ii) a proposição de que $\mathrm{R}(\mathrm{P} 1, \mathrm{P} 2, \ldots, \mathrm{Pn})$ implica logicamente a proposição que é o valor de $\mathrm{K}(\mathrm{P} 1, \mathrm{P} 2, \ldots, \mathrm{Pn})$.

A ideia de Tooley (1977, p. 679) é que poderíamos especificar diferentes relações nomológicas - como a necessitação, a exclusão ou outras - por meio de diferentes funções de construção $R$, que mapeariam, grupos de universais a certas proposições que seriam os valores de K. Por exemplo, a necessitação nômica seria "uma função de construção que mapeia pares ordenados de universais $(\mathrm{P}, \mathrm{Q})$ em proposições da forma $\forall \mathrm{x}(\mathrm{Px} \rightarrow \mathrm{Qx})$ "; e a exclusão nômica poderia ser vista como outra função de construção que mapeia os universais (P;Q) em proposições da forma $\forall \mathrm{x}(\mathrm{Px} \rightarrow \sim \mathrm{Qx})$. E uma "frase nomológica verdadeira" poderia ser definida, segundo Tooley (1977, p. 679), do seguinte modo:

S é uma frase nomológica verdadeira sse há uma proposição p que é expressa por $\mathrm{S}$ e há uma relação nomológica $\mathrm{R}$, uma função de construção associada $\mathrm{K}$ e os universais $\mathrm{P} 1, \mathrm{P} 2, \ldots, \mathrm{Pn}$, tal que

(1) não é logicamente necessário que p;

(2) a proposição de que p é idêntica ao valor de K(P1, P2, ..., Pn);

(3) é verdade que $\mathrm{R}(\mathrm{P} 1, \mathrm{P} 2, \ldots, \mathrm{Pn})$;

(4) não é logicamente necessário que $\mathrm{R}(\mathrm{P} 1, \mathrm{P} 2, \ldots, \mathrm{Pn})$;

(5) a proposição de que $\mathrm{R}(\mathrm{P} 1, \mathrm{P} 2, \ldots, \mathrm{Pn})$ implica logicamente a proposição de que $\mathrm{p}$.

A diferença entre uma frase nomológica e uma frase de lei seria apenas que a frase de lei não teria condições irrelevantes. Mas no que diz respeito ao nosso assunto aqui tratado, essa diferença é irrelevante.

Porém, a diferença mais significativa com relação ao Armstrong é a não aceitação por Tooley do Princípio de Instanciação. 
Este acredita que os seus casos nos mostram situações em que deveríamos postular leis universais não derivadas e não instanciadas, pois elas seriam os únicos veridadores possíveis dos contrafactuais dos Casos de Tooley e dos enunciados de leis não derivadas e não instanciadas. Essa é a motivação fundamental para aceitarmos o substantivismo ante rem e os universais não instanciados que ele postula. Todas as outras teorias falham nesse ponto, mas o ante rem, não.

Essa vantagem é fundamental justamente, pois os casos de Tooley nos fornecem situações possíveis com relação ao nosso mundo, que nos forçariam a postular leis não instanciadas. Essas situações são possíveis, pois elas são actuais ${ }^{33}$ (ou porque há análogos actuais). As razões para pensarmos que tais possibilidades são actuais são que, primeiramente, há evidências de tipos de situações nunca instanciadas, como o encontro de um composto do mesmo tipo que me forma com algo do mesmo tipo da Galáxia de Andrômeda. E há situações que resultariam em catástrofes, segundo nossas teorias, as quais fazemos de tudo para evitar sua instanciação. As leis que regeriam tais situações só poderiam ser adequadamente descritas pelo substantivista ante rem. E, na medida em que outras teorias não podem explicar os Casos de Tooley, elas se tornam teorias que não conseguem descrever casos tanto possivelmente existentes, quanto atualmente existentes.

Um problema que me parece que poderia ser levantado contra o substantivismo ante rem de Tooley, no que diz respeito aos seus casos, é que não é nada claro como as relações entre universais, se forem funções de construção que mapeiam os universais em proposições, poderão existir na natureza e relacionar os universais com os particulares. Armstrong (1983), ao tomar essa relação como a necessitação, torna clara qual relação poderia haver entre universais e também como essa relação entre os universais pode explicar a regularidade.

33 Apelo aqui ao axioma da lógica modal $\mathrm{A} \rightarrow \diamond \mathrm{A}$.

Manuscrito - Rev. Int. Fil., Campinas, v. 36, n. 1, p. 67-101, jan.-jun. 2013. 
Tooley (1977) acredita que utilizar as funções de construção é uma boa opção, pois ele acredita que se aceitarmos apenas relação de necessitação, ou ela junto com a relação de exclusão, teremos certos problemas. Uma razão para rejeitarmos uma metafísica que aceite apenas a relação de necessitação nômica entre os universais seria que, ao menos prima facie, ela não pode fornecer as condições de verdade de leis de exclusão - leis com a forma " $\forall \mathrm{x}(\mathrm{Fx} \rightarrow \sim \mathrm{Gx})$ " - a não ser que aceite universais negativos - como o universal de ser $\sim$ G. Tanto Armstrong (1983), quanto Tooley (1977) pensam que há razões independentes para rejeitarmos universais negativos. E é por isso que Tooley atesta que se quisermos dar conta de tais leis sem aceitar universais negativos, temos de aceitar, além da relação de necessitação, a relação de exclusão.

Por sua vez, Armstrong sai desse problema, pensando as leis de exclusão como derivadas a partir de leis não derivadas de necessitação. $\mathrm{E}$ as leis probabilísticas como relações de probabilificação entre universais (que são relações de probabilidade de necessitação). Como a solução de Armstrong também está aberta ao substantivista ante rem, ele pode, contrariamente a Tooley, defender que as leis não são funções de construção, mas são relações universais ante rem de necessitação entre outros universais ante rem. Se for esse o caso, então a objeção das funções de construção não poderia ser traçada contra o substantivista ante rem, a não ser que a própria relação de necessitação fosse colocada em causa. ${ }^{34}$

34 Entretanto, mesmo que sanemos o problema das exclusões, Tooley (1977, p. 677) nos mostra que ainda persistiriam alguns problemas na forma da expressão de uma lei. Se houvesse leis não deterministas, elas poderiam ser expressas por $\forall \mathrm{x}(\mathrm{Fx} \rightarrow(\mathrm{Gx}$ v Hx $))$, e não é claro como tais leis seriam expressas em termos de necessitação e exclusão. Para utilizarmos apenas a necessitação e a exclusão, precisaríamos aceitar universais disjuntivos, coisa que a maioria dos filósofos costuma rejeitar. É claro que isso só é realmente um problema apenas se existirem leis probabilísticas. Mas se existirem tais leis, Armstrong (1983) poderia fornecer uma abordagem para elas por meio da

Manuscrito - Rev. Int. Fil., Campinas, v. 36, n. 1, p. 67-101, jan.-jun. 2013. 
Uma outra solução, essa não disponível nem para Armstrong e nem para Tooley, é dizer que as leis de necessitação determinam todos os mundos metafisicamente possíveis ${ }^{35}$; e, assim, igualmente, determinam todas as impossibilidades e, consequentemente, as exclusões - sem inflacionamento ontológico. Essa solução não está disponível para nenhum dos dois teóricos indicados, pois eles sustentam que as relações entre universais são contingentes, de modo que não se mantém em todos os mundos possíveis em nenhum sentido de "todos os mundos possíveis"; e, portanto, não podem determinar impossibilidades em nenhum sentido de "impossibilidades".

Isso nos leva a um outro possível foco de objeção, que é o fato de as leis de Armstrong e Tooley serem relações contingentes entre universais, por mais que sejam relações de necessitação. Se as relações entre os universais que formam as leis são contingentes, elas não podem fundamentar a contrafactualidade, pois haverá mundos em que há instâncias dos universais que ela relaciona e em alguns deles as instâncias não obedecerão as leis. E, se as leis de necessitação contingente não puderem salvar a contrafactualidade, então elas não poderão ser os veridadores dos contrafactuais dos Casos de Tooley (e nem das leis científicas).

Assim, para que o substantivismo ante rem possa realmente fornecer uma abordagem satisfatória para os Casos de Tooley, é preciso que ele sustente que as leis são não relações de necessitação contingente, como sustentam Armstrong e Tooley, mas sim relações de necessitação fracamente necessária ou fortemente necessária.36 Isso

relação de probabilificação, que poderia ser emulada pelo substantivista ante rem.

35 Em alguma abrangência apropriada e ainda não trabalhada de "todos os mundos possíveis", sejam todos os mundos fisicamente possíveis, todos os mundos logicamente possíveis etc.

36 Reparemos que o substantivista in rebus pode aceitar a necessitação fracamente necessária também, mas contrariamente não pode aceitar a necessitação fortemente necessária, já que sustenta o PI.

Manuscrito - Rev. Int. Fil., Campinas, v. 36, n. 1, p. 67-101, jan.-jun. 2013. 
porque é apenas se houver uma invariância da lei em todos os mundos possíveis (seja em todos os mundos em que há instâncias de seus universais, seja em todos os mundos possíveis sem restrições) que poderemos garantir a contrafactualidade. E é preciso garantir a contrafactualidade - indicando os veridadores dos contrafactuais (ou dizendo por que eles são falsos) - para explicarmos satisfatoriamente os Casos de Tooley.

\section{Conclusão}

O que viemos vendo neste artigo é que os Casos de Tooley colocam um problema sério às teorias com relação à natureza das leis naturais, pois indicam situações possíveis análogas a situações actuais, que só poderiam ser descritas por uma das posições teóricas com relação às leis, se esta for levemente modificada. Se esse for o caso, teremos encontrado boas razões para preferir tal teoria frente às outras - o que não é surpreendente, já que o substantivismo radical de Tooley é construído justamente com essa intenção. O que eu tentei fornecer aqui foram apenas mais razões para preferirmos o substantivismo ante rem às suas alternativas.

Analisamos primeiro o conectivismo e vimos que ele apresenta tanto problemas com relação à universalidade dos contrafactuais verdadeiros nos Casos de Tooley, que não poderia ser explicada por disposições de objetos particulares, quanto problemas de sobredeterminação e de regresso ao infinito, caso esqueçamos os problemas de universalidade.

O regularista, por sua vez, teve problemas em impedir que regularidades humeanas contraditórias fossem o caso quando não houvesse instâncias da antecedente da condicional que expressa a regularidade. vimos que ele escapa a esse problema modificando a forma da regularidade de modo a exigir um importe existencial tanto da antecedente, quanto da consequente da condicional em causa. No 
entanto, mesmo assim, ele não é capaz de resolver a questão central dos Casos de Tooley, que é encontrar os veridadores de certos contrafactuais. O regularista estaria comprometido a falar que os contrafactuais dos Casos de Tooley não são verdadeiros, pois suas leis não teriam necessidade alguma ${ }^{37}$. O problema de o regularista falar tal coisa é que isso seria contra a sua própria motivação de dar conta também das leis científicas, que têm uma certa força contrafactual, e da aceitação dos cientistas de que os contrafactuais dos Casos de Tooley seriam verdadeiros nos Casos de Tooley.

Armstrong também observa que o substantivismo in rebus tem que fornecer uma abordagem para os contrafactuais dos Casos de Tooley. Ele faz isso em termos de leis de segunda ordem que seriam veridadores de alguns contrafactuais sobre a existência de leis de primeira ordem. O problema de sua abordagem é que a partir de tais tipos de leis de ordem superior não é possível deduzir as leis de ordem inferior que gostaríamos para fornecer veridadores para os contrafactuais de Tooley. O que deveria ser deduzido da lei de ordem superior, a fim de que o contrafactual em causa tenha veridador, é a própria lei de ordem inferior, e não que haveria uma lei de ordem inferior, caso as propriedades em causa estivessem instanciadas.

37

O regularismo sofisticado, por meio do realismo de mundos possíveis de Lewis $(1973,1986)$, tenta fornecer uma abordagem para os veridadores de contrafactuais em termos de o que é o caso em mundo próximos. O problema é que tal teoria já pressupõe que os mundos mais próximos são os que têm as mesmas leis. E não podemos pressupor tal coisa e concluir o mesmo sem cair em petição de princípio. Se, de outro modo, não utilizamos as leis para explicar os contrafactuais, como parece ser o caminho regularista de Lewis, então que algo seja uma verdade contrafactual é simplesmente um fato bruto da pluralidade de mundos (e, consequentemente, que os mundos próximos têm as mesmas leis seria também um fato bruto sem explicação). O problema disso é que faz as leis naturais não poderem cumprir os papéis que os cientistas gostariam que as leis cumprissem (como explicar a verdade contrafactual), indo portanto contra uma das motivações centrais de uma metafísica das leis, que é ter uma teoria aceitável para dar conta das ciências.

Manuscrito - Rev. Int. Fil., Campinas, v. 36, n. 1, p. 67-101, jan.-jun. 2013. 
É apenas, então, com o substantivismo ante rem que podemos fornecer uma abordagem satisfatória dos Casos de Tooley. Mas mostramos que o próprio Tooley, por oferecer uma abordagem em termos de funções de construção mapeando universais em proposições, não consegue a clareza necessária - que Armstrong expressou com sua relação de necessitação - para nos mostrar como se daria a relação entre as leis, seus universais e os particulares. Além disso, por postular relações contingentes entre universais, perde a explicação da contrafactualidade, coisa que não pode perder, se quiser explicar seus próprios casos. A única solução viável para o substantivismo ante rem explicar os Casos de Tooley é falar que as relações entre os universais são relações de necessitação necessárias em algum sentido ${ }^{38}$.

Assim, como esses problemas não são fatais para o teórico ante rem e como as outras teorias tem problemas fatais com relação aos Casos de Tooley, a teoria ante rem é a única que pode fornecer uma abordagem satisfatória a tais casos. E, se tais casos forem tanto possíveis, quanto atuais (ou com análogos atuais), então qualquer boa teoria das leis deve ser apta a descrevê-los.

\section{Referências Bibliográficas}

ARMSTRONG, D. What is a law of nature?. Cambridge: Cambridge University Press, 1983.

BEROFSKY, B. “The Regularity Theory”. Nôus: 2/4, pp. 315-340, 1968.

38 O que quero dizer com "necessárias em algum sentido" aqui é que teremos que aceitar que as leis são ou fortemente necessárias, ou fracamente necessárias, e que elas ou são fisicamente necessárias, ou metafisicamente necessárias, ou que são necessárias em algum outro sentido ainda. O ponto fundamental aqui é que não podemos aceitá-las como relações de necessitação contingente e nem como relações meramente contingentes sem perder a contrafactualidade. Agora, saber em qual sentido as leis são necessárias, isso é um assunto por demais extenso para tratarmos neste artigo.

Manuscrito - Rev. Int. Fil., Campinas, v. 36, n. 1, p. 67-101, jan.-jun. 2013. 
BIRD, A. "Necessarily, salt dissolves in water". Analysis: vol. 61, n. 4, 2001. 2007.

BLACKBURN, S. Essays in Quasi-Realism. Oxford: Oxford University Press,1993.

CID, R. "O Dilema da Continuidade da Matéria". Revista do Seminário dos Alunos do Programa de Pós-Graduação em Lógica e Metafísica da UFRJ: vol. 2, 2011.

ELLIS, B. The Metaphysics of Scientific Realism. Wiltshire: Cromwell Press Group, 2009.

HUME, D. (1777). Enquiries Concerning Human Understanding and Concerning the Principles of Morals; L. A. Selby-Bigge (introduction). 2a ed. Oxford: Clarendon Press, 1902.

LANGE, M. Laws and Lawmakers. Oxford: Oxford University Press, 2009.

LEWIS, D. Counterfactuals. Oxford: Blackwell, 1973.

. On the plurality of worlds. Oxford: Basil Blackwell, 1986.

MUMFORD, S. Laws in Nature, London: Routledge, 2004.

TOOLEY, M. "The Nature of Laws". Canadian Journal of Philosophy: 7/4, 1977.

SWARTZ, N. "Laws of Nature". Internet Encyclopedia of Philosophy, 2001. Disponível em http://www.iep.utm.edu/lawofnat/ e acessado em 12/03/2011. 


\section{ERRATA}

No artigo "As leis da natureza e os casos de Tooley" publicado no número 1, volume 36, de Manuscrito - Revista Internacional de Filosofia, na página 70 , onde se lê:

“(...) elas se adequam à visão científica de leis científica."

\section{Leia-se:}

“(...) elas se ajustam à visão científica de leis."

No mesmo artigo, na página 100, onde de lê:

"Dessa maneira, como esses problemas), então qualquer boa teoria das leis deve ser apta a descrevê-los."

\section{Leia-se:}

"Assim, como esses problemas não são fatais para o teórico ante rem e como as outras teorias tem problemas fatais com relação aos Casos de Tooley, a teoria ante rem é a única que pode fornecer uma abordagem satisfatória a tais casos. E, se tais casos forem tanto possíveis, quanto atuais (ou com análogos atuais), então qualquer boa teoria das leis deve ser apta a descrevê-los." 